\title{
Article
}

\section{Effects of prophylactic knee bracing on knee joint kinetics and kinematics during netball specific movements}

Sinclair, Jonathan Kenneth, Vincent, Hayley and Richards, Jim Available at http://clok.uclan.ac.uk/15337/

Sinclair, Jonathan Kenneth ORCID: 0000-0002-2231-3732, Vincent, Hayley and Richards, Jim ORCID: 0000-0002-4004-3115 (2016) Effects of prophylactic knee bracing on knee joint kinetics and kinematics during netball specific movements. Physical Therapy in Sport . ISSN 1466-853X

It is advisable to refer to the publisher's version if you intend to cite from the work. http://dx.doi.org/10.1016/j.ptsp.2016.08.005

For more information about UCLan's research in this area go to http://www.uclan.ac.uk/researchgroups/ and search for <name of research Group>.

For information about Research generally at UCLan please go to http://www.uclan.ac.uk/research/

All outputs in CLoK are protected by Intellectual Property Rights law, including Copyright law. Copyright, IPR and Moral Rights for the works on this site are retained by the individual authors and/or other copyright owners. Terms and conditions for use of this material are defined in the policies page. 
Original Research

\title{
Effects of prophylactic knee bracing on knee joint kinetics and kinematics during netball specific movements
}

\author{
Jonathan K. Sinclair ${ }^{\text {a, * , Hayley Vincent }}{ }^{\text {a, b }}$, Jim D. Richards ${ }^{\text {b }}$ \\ ${ }^{a}$ Centre for Applied Sport and Exercise Sciences, School of Sport and Wellbeing, College of Health and Wellbeing, University of Central Lancashire, Lancashire, UK \\ ${ }^{\mathrm{b}}$ Allied Health Research Unit, School of Health Sciences, College of Health and Wellbeing, University of Central Lancashire, Lancashire, UK
}

\section{A R T I C L E IN F O}

\section{Article history:}

Received 25 February 2016

Received in revised form 11 July 2016

Accepted 9 August 2016

Available online $\mathrm{xxx}$

\section{Keywords:}

Biomechanics

Netball

Knee brace

Injury

\begin{abstract}
A B S T R A C T
Objective

To investigate the effects of a prophylactic knee brace on knee joint kinetics and kinematics in netball specific movements.

Design

Repeated measures; Setting: Laboratory; Participants: Twenty university first team level female netball players. Outcome measurements

Participants performed three movements, run, cut and vertical jump under two conditions (brace and no-brace). 3-D knee joint kinetics and kinematics were measured using an eight-camera motion analysis system. Knee joint kinetics and kinematics were examined using $2 \times 3$ repeated measures ANOVA whilst the subjective ratings of comfort and stability were investigated using chi-squared tests.

Results

The results showed no differences $(\mathrm{p}>0.05)$ in knee joint kinetics. However the internal/external rotation range of motion was significantly $(\mathrm{p}<0.05)$ reduced when wearing the brace in all movements. The subjective ratings of stability revealed that netballers felt that the knee brace improved knee stability in all movements.

Conclusions

Further study is required to determine whether reductions in transverse plane knee range of motion serve to attenuate the risk from injury in netballers.
\end{abstract}

(C) 2016 Published by Elsevier Ltd.

\section{Introduction}

Netball represents a team sport with a high level of participation in over 70 countries (Hetherington, King, Visentin, \& Bird, 2009). Netball is a physical demanding activity characterized by dynamic movements such as jumping and cutting and also moderate actions such as jogging (Neal \& Sydney-Smith, 1992). Netball is considered to be associated with a relatively high rate of non-contact injuries. During tournament games 238 injuries were observed per 1000 playing hours (Hume \& Steele, 2000), Saunders and Otago (2009) further documented from three seasons of competition that injury rates range from 66.7 to 71.4 per 1000 participants. These analyses have shown that the majority of injuries are chronic in nature and occur predominantly in the lower extremities (McManus, Stevenson, \& Finch, 2006). The knee has been shown to be the most commonly injured musculoskeletal structure in netball players, accounting for $24 \%$ of total injuries (Hopper, 1997; Hume \& Steele, 2000).

\footnotetext{
* Corresponding author. Centre for Applied Sport Exercise and Nutritional Sciences, School of Sport and Wellbeing, University of Central Lancashire, Preston, Lancashire, PR1 2HE, UK

Email address: jksinclair@uclan.ac.uk (J.K. Sinclair)
}

Knee braces are utilized extensively in dynamic sports such as netball in order to prevent knee injuries. Knee braces are external, non-adhesive devices which aim to influence the position of the patella and improve knee alignment (Paluska \& McKeag, 2000). They include medial and lateral vertical hinges, which may be uniaxial or polyaxial, and a mechanism to limit hyperextension (Martin \& the Committee on Sports Medicine and Fitness, 2001). Knee braces are considered an inexpensive modality that can be applied by the wearer without assistance from a clinician (Warden et al., 2008; Paluska \& McKeag, 2000) and a well-fitting knee brace can be utilized during normal daily activities and also during sports tasks (Warden et al., 2008). Prophylactic knee braces are designed to protect athletes from sustaining injuries without reducing knee mobility, although there is scant evidence to support their efficacy in protecting the knee joint from injury (Warden et al., 2008). Functional knee braces are intended to increase knee stability following a previous injury and to reduce the likelihood of further injuries.

The effects of knee bracing have been studied extensively in a range of sports movements. However, there has yet to be any published information concerning the effects of knee bracing in netball players during sport specific movements. Therefore the aim of the current investigation was to investigate the effects of a prophylactic knee brace on knee joint kinetics and kinematics in netball specific movements. 


\section{Methods}

\subsection{Participants}

Twenty female netball players (age $=20.95 \pm 1.76$ years, height $=1.67 \pm 0.04 \mathrm{~m}$, mass $=61.45 \pm 7.04 \mathrm{~kg}$ ) were recruited to for this study. The participants were university first team level players and had a minimum of 3 years of competitive netball experience. All participants were free from lower extremity pathology at the time of data collection and had not suffered from a knee injury in the last five years. Written informed consent was provided in accordance with the declaration of Helsinki. The procedure was approved by a university ethics committee.

\subsection{Procedure}

A single knee brace was used in this study, (Trizone, DJO USA), which came in three different sizes; small, medium and large to accommodate all participants (Fig. 1). The Trizone is a silicone reinforced compression sleeve with a circular knit construction which aims to provide mild support and enhanced proprioception to the knee through targeted zonal compression. The brace was worn on the dominant limb. Kinematic information from the lower extremity joints was obtained using an eight camera motion capture system (Qualisys Medical AB, Goteburg, Sweden) using a capture frequency of $250 \mathrm{~Hz}$. Dynamic calibration of the system was performed before each data collection session. To measure kinetic information an embedded piezoelectric force platform (Kistler National Instruments, Model 9281CA) operating at $1000 \mathrm{~Hz}$ was utilized. The kinetic and kinematic information were synchronously obtained and interfaced using Qualisys track manager. To control for any sequence effects the order in which participants performed in the brace and no-brace conditions was randomized.

Lower extremity segments were modelled using the calibrated anatomical systems technique (Cappozzo, Catani, Leardini, Benedeti,
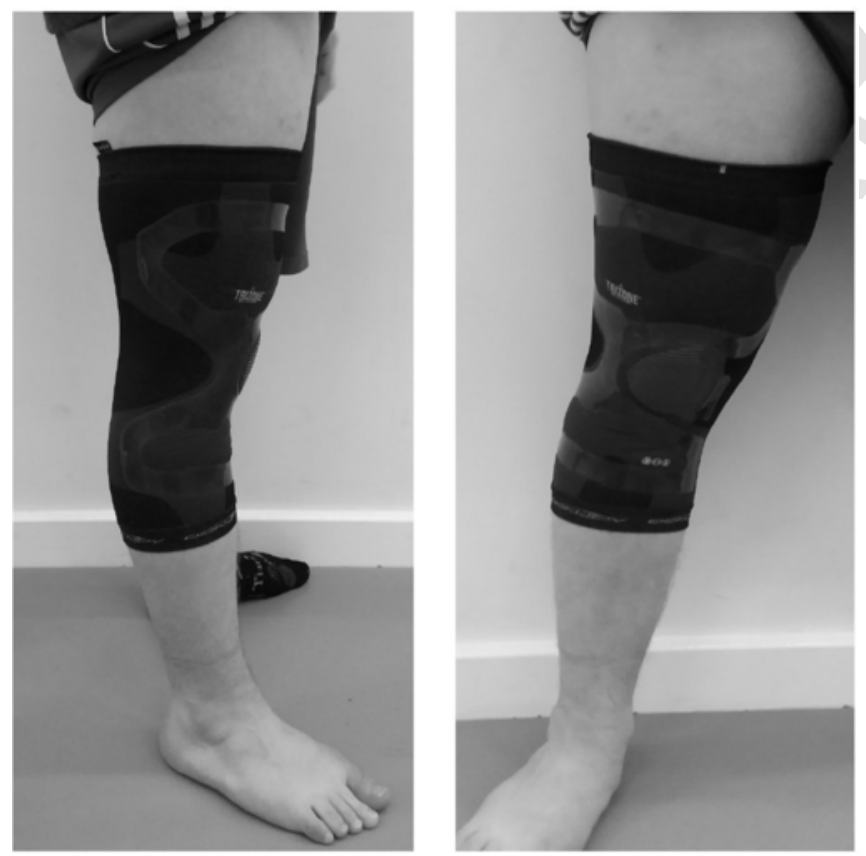

Fig. 1. Experimental knee brace.
\& Della, 1995), to allow knee joint kinetics and kinematics to be quantified. Retroreflective markers $(19 \mathrm{~mm})$ were positioned unilaterally allowing the shank and thigh to be defined. The shank was defined via the medial and lateral malleoli and medial and lateral femoral epicondyles and tracked using a cluster positioned onto the shank. The thigh was defined via the medial and lateral femoral epicondyles and the hip joint centre and tracked using a cluster positioned onto the thigh. To define the pelvis additional markers were positioned onto the anterior (ASIS) and posterior (PSIS) superior iliac spines and this segment was tracked using the same markers. The hip joint centre was determined using a regression equation that uses the positions of the ASIS markers (Sinclair et al., 2013a, b). The centre of the knee and ankle joints were delineated as the mid-point between the femoral epicondyle and malleoli markers (Graydon, Fewtrell, Atkins, \& Sinclair, 2015; Sinclair, Chockalingam, Naemi, \& Vincent, 2015). Static calibration trials were obtained allowing for the anatomical markers to be referenced in relation to the tracking markers/clusters. The $\mathrm{Z}$ (transverse) internal/external rotation axis was oriented vertically from the distal segment end to the proximal segment end. The Y (coronal) adduction/abduction axis was oriented in the segment from posterior to anterior. Finally, the X (sagittal) flexion/extension axis orientation was determined using the right hand rule and was oriented from medial to lateral.

Data were collected during run, cut and jump movements according to below:

\subsection{Run}

Participants ran at $4.0 \mathrm{~m} \mathrm{~s}^{-1} \pm 5 \%$ and struck the force platform with their right (dominant) limb (Sinclair et al., 2015a, b). Participants commenced their movement a minimum of 20 feet away from the force platform. The average velocity of running was monitored using infra-red timing gates (SmartSpeed Ltd UK). The stance phase of running was defined as the duration over $>20 \mathrm{~N}$ of vertical force was applied to the force platform.

\subsection{Cut}

For the cut movement participants used an approach velocity of $4.0 \mathrm{~m} \mathrm{~s}^{-1} \pm 5 \%$ and struck the force platform with their right (dominant) limb (Sinclair et al., 2015a, b). Participants were required change direction to the opposite side at a $45^{\circ}$ angle. As with the run movement participants commenced their movement a minimum of 20 feet away from the force platform. In accordance with McLean, Huang, Su, and Van Den Bogert (2004) cut angles were measured from the centre of the force plate and the corresponding line of movement was delineated using masking tape so that it was clearly evident to participants. The stance phase of the cut-movement was similarly defined as the duration over $>20 \mathrm{~N}$ of vertical force was applied to the force platform.

\subsection{Jump}

Participants completed counter movement vertical jumps in which they were required to use full arm swing and also to commence and land the jump on the force platform. The landing phase of the jump movement was quantified and was considered to have begun when $>20 \mathrm{~N}$ of vertical force was applied to the force platform and ended at point of maximum knee flexion.

Finally, participants were asked to subjectively rate the Trizone knee sleeve in relation to performing the movements without the brace in terms of stability and comfort. This was accomplished using 
3 point scales that ranged from $1=$ very comfortable, $2=\mathrm{Ok}$ and $3=$ very uncomfortable and $1=$ very stable, $2=$ no change and $3=$ very unstable.

\subsection{Data processing}

Dynamic trials were processed using Qualisys Track Manager and then exported as C3D files. GRF and marker data were filtered at $50 \mathrm{~Hz}$ and $15 \mathrm{~Hz}$ respectively using a low-pass Butterworth 4th order filter and processed using Visual 3-D (C-Motion, Germantown, MD, USA). Joint kinetics were computed using Newton-Euler inverse-dynamics, allowing net knee joint moments to be calculated. Angular kinematics of the knee joint were calculated using an XYZ (sagittal, coronal and transverse) sequence of rotations. To quantify knee joint moments segment mass, segment length, GRF and angular kinematics were utilized using the procedure previously described by Sinclair (2014). The net joint moments were normalized by dividing by body mass $(\mathrm{Nm} / \mathrm{kg})$. Knee joint kinetic and kinematic measures from the stance (run and cut movements) and landing (jump movement) phases which were extracted for statistical analysis were 1) maximum angle, 2) minimum angle 3 ) relative range of motion (representing the angular displacement from maximum angle to minimum angle) and 4) peak joint moment.

In addition patellofemoral loading was examined through extraction of 1) peak patellofemoral contact force (PTCF) and 2) peak patellofemoral contact pressure (PTS). PTCF was normalized by dividing the net PTCF by body mass (N/kg). PTCF during the stance (run and cut movements) and landing (jump movement) phases was estimated using knee flexion angle (kf) and knee extensor moment (KEM) through the biomechanical model of Ho, Blanchette, and Powers (2012). The sensitivity index of this model was validated by Sinclair et al. (2015a, b), and this technique has been shown to sufficiently sensitive to detect differences in PTCF and PTS when wearing a knee brace vs. no brace (Sinclair et al., 2016). The effective moment arm of the quadriceps muscle (QM) was calculated as a function of $\mathrm{kf}$ using a non-linear equation, based on information presented by van Eijden, Kouwenhoven, Verburg, and Weijs (1986):

$$
\mathrm{QM}=0.00008 \mathrm{kf}^{3}-0.013 \mathrm{kf}^{2}+0.28 \mathrm{kf}+0.046
$$

The force $(\mathrm{N})$ of the quadriceps $(\mathrm{FQ})$ was calculated using the below formula:

$\mathrm{FQ}=\mathrm{KEM} / \mathrm{QM}$

Net PTCF (N) was estimated using the FQ and a constant (C):

$\mathrm{PTCF}=\mathrm{FQ} \times \mathrm{C}$

The $\mathrm{C}$ was described in relation to $\mathrm{kf}$ using a curve fitting technique based on the non-linear equation described by van Eijden et al. (1986):

$$
\mathrm{C}=\left(0.462+0.00147 \times \mathrm{kf}^{2}-0.0000384 \times \mathrm{kf}^{2}\right) /(1-0.0162 \times \mathrm{kf}+0.00
$$

PTS (MPa) was calculated using the net PTCF divided by the patellofemoral contact area. The contact area was described using the
Ho et al. (2012) recommendations by fitting a 2 nd order polynomial curve to the data of Powers, Lilley, and Lee (1998) showing patellofemoral contact areas at varying levels of $\mathrm{kf}$.

$\mathrm{PTS}=\mathrm{PTCF} /$ contact area

\subsection{Analyses}

Statistical differences were examined using 2 (Brace vs no-brace) x 3 (Movement) repeated measures analysis of variance (ANOVA) with statistical significance accepted at the $\mathrm{p} \leq 0.05$ (Sinclair et al., $2013 \mathrm{a}, \mathrm{b})$. Effect sizes were calculated using partial eta squared $\left(\mathrm{p} \eta^{2}\right)$. Effect sizes was characterized as follows: small $=p \eta^{2}<0.40$; medium $=p \eta^{2} \geq 0.40$ and $<0.70 ;$ large $\left.=p \eta^{2} \geq 0.70\right)$. Using the data collected from the subjective feedback based on participants' opinion on the stability and comfort of the knee sleeve in each movement were examined using Chi-Square tests. Statistical tests were conducted using SPSS v22 (SPSS Inc, Chicago, USA).

\section{Results}

\subsection{Patellofemoral kinetics}

No significant $(\mathrm{p}>0.05)$ differences in patellofemoral kinetics were observed (Fig. 2).
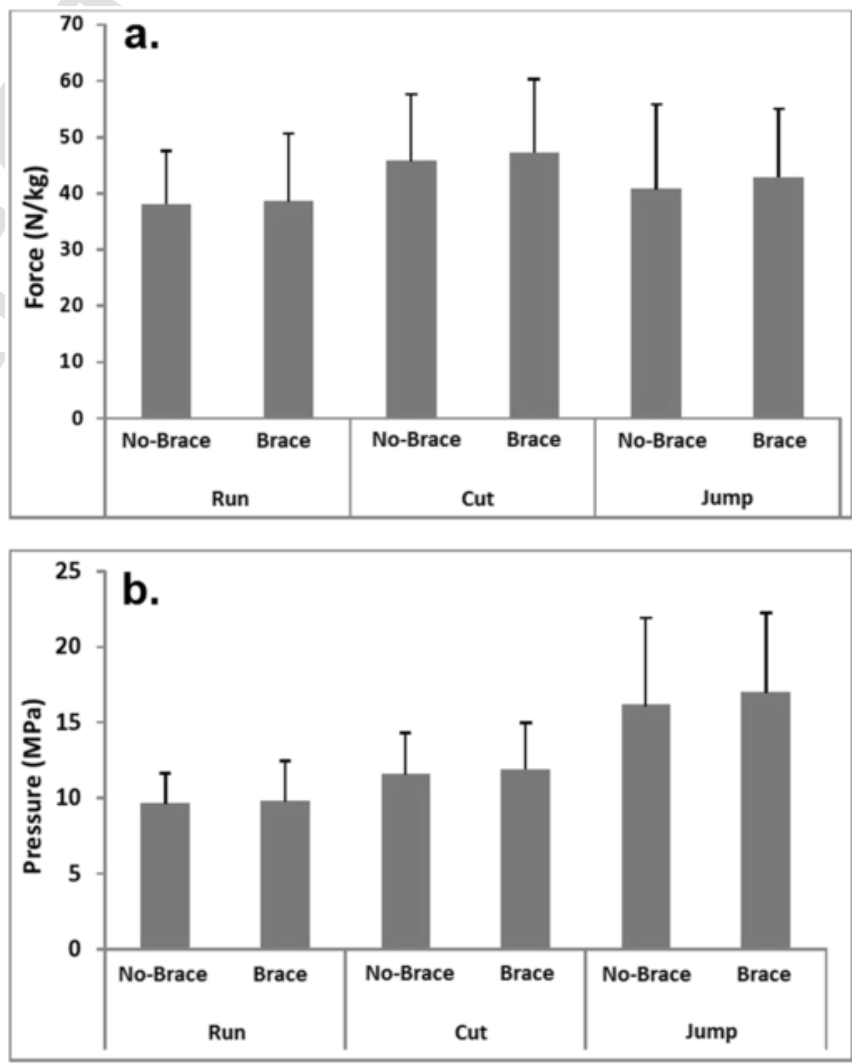

Fig. 2. Mean and SD patellofemoral joint kinetics during brace and no-brace conditions $(\mathrm{a}=$ patellofemoral force $(\mathrm{PTCF}) \& \mathrm{~b}=$ patellofemoral pressure (PTS)). 


\subsection{Joint kinematics}

In the transverse plane the results showed there was a significant reduction in internal/external rotation range of motion when wearing the knee brace in all movements, $\mathrm{p} \leq 0.05, \mathrm{p}^{2}=0.47$ (Table 1 ).

\subsection{Joint kinetics}

No significant $(\mathrm{p}>0.05)$ differences in joint kinetics were observed (Table 2).

\subsection{Subjective feedback}

For the subjective ratings of comfort there were no significant changes as a function of wearing the knee brace. For stability significantly more participants found that the knee brace provided improved stability during the run $\left(X^{2}=4.05, p<0.05\right)$, cut $\left(X^{2}=3.99, p<0.05\right)$ and jump $\left(\mathrm{X}^{2}=4.15, \mathrm{p}<0.05\right)$ movements.

\section{Discussion}

The aim of the current investigation was to determine the effects of an acute prophylactic knee brace on knee joint kinetics and kinematics in netball specific movements. To the authors knowledge this represents the first investigation to examine the biomechanical effects of prophylactic knee bracing in netball specific movements.

The first key observation from the current research is that knee bracing did not significantly influence joint kinetics in any of the movements. This finding disagrees with those of Lindenfeld, Hewett, and Andriacchi (1997) and Pagani, Potthast, and Brüggemann (2010) who demonstrated reductions in knee kinetic parameters whilst wearing knee braces, but does concur with the observations of Gaasbeek, Groen, Hampsink, Van Heerwaarden, and Duysens (2007) or Sinclair et al., (2016). It is proposed that this disagreement between studies may relate to the wide range of different of knee braces and participant groups that have been used in biomechanical and clinical research settings. For instance Sinclair et al., (2016) showed that a knee sleeve significantly reduced patellofemoral loading in athletes with patellofemoral pain and Gaasbeek et al. (2007) showed that peak varus moment was significantly reduced when using a valgus knee brace in patients with medial compartment osteoarthritis. Excessive PTCF and PTS are considered to be one of the key mechanisms linked to the aetiology of knee pathologies in athletic populations (Ho et al., 2012). Therefore the key implication from this observation is that prophylactic bracing does not reduce the knee kinetic parameters that have been linked to the aetiology of knee pathologies.

The findings from this work did show however that the knee brace served to reduce internal/external rotation range of motion in all movements. This finding supports those of Giotis et al., (2011; 2013) who showed similar reductions in transverse plane tibial rotation with the introduction of knee bracing. Excessive transverse plane movement at the knee may be pertinent to the aetiology of knee pathologies (Hemmerich, van der Merwe, Batterham, \& Vaughan, 2011). Therefore, it can be speculated that prophylactic knee bracing may be able to attenuate the risk of knee pathology in netballers, although further prospective work is required to fully establish this. It should also be noted that this finding was observed when performing fully anticipated and controlled movements in a laboratory setting, and

Table 1

Knee kinematics as a function of both brace and movement conditions.

\begin{tabular}{|c|c|c|c|c|c|c|c|c|c|c|c|c|}
\hline & \multicolumn{6}{|c|}{ No brace } & \multicolumn{6}{|l|}{ Brace } \\
\hline & \multicolumn{2}{|l|}{ Run } & \multicolumn{2}{|l|}{ Cut } & \multicolumn{2}{|l|}{ Jump } & \multicolumn{2}{|l|}{ Run } & \multicolumn{2}{|l|}{ Cut } & \multicolumn{2}{|l|}{ Jump } \\
\hline & Mean & $\mathrm{SD}$ & Mean & SD & Mean & SD & Mean & SD & Mean & SD & Mean & SD \\
\hline \multicolumn{13}{|c|}{ Sagittal plane $(+=$ flexion $/-=$ extension $)$} \\
\hline Peak Range of Motion $\left({ }^{\circ}\right)$ & 24.61 & 4.60 & 34.12 & 7.24 & 64.12 & 15.81 & 25.21 & 3.00 & 34.63 & 5.11 & 62.93 & 10.81 \\
\hline Maximum angle $\left({ }^{\circ}\right)$ & 44.73 & 4.11 & 52.31 & 6.86 & 85.22 & 17.11 & 42.86 & 4.79 & 52.16 & 6.44 & 85.00 & 11.39 \\
\hline Minimum angle $\left({ }^{\circ}\right)$ & 20.12 & 4.57 & 18.19 & 4.51 & 21.10 & 4.22 & 17.66 & 4.18 & 17.53 & 3.88 & 21.07 & 6.48 \\
\hline \multicolumn{13}{|c|}{ Coronal plane $(+=$ adduction $/-=$ abduction $)$} \\
\hline Peak Range of Motion $\left({ }^{\circ}\right)$ & 8.23 & 4.11 & 8.84 & 3.25 & 9.88 & 3.53 & 6.70 & 2.81 & 9.50 & 3.04 & 10.62 & 3.13 \\
\hline Maximum angle $\left({ }^{\circ}\right)$ & -0.86 & 3.70 & -2.68 & 3.39 & -2.19 & 3.72 & -2.24 & 2.95 & -3.32 & 3.12 & -3.83 & 4.63 \\
\hline Minimum angle $\left({ }^{\circ}\right)$ & -9.09 & 4.67 & -11.51 & 5.82 & -12.08 & 5.17 & -9.24 & 4.52 & -12.82 & 4.79 & -14.46 & 5.59 \\
\hline \multicolumn{13}{|c|}{ Transverse plane $(+=$ internal $/-=$ external $)$} \\
\hline Peak Range of Motion $\left(^{\circ}\right)$ & 19.76 & 5.67 & 18.04 & 4.66 & 8.85 & 2.78 & 15.91 & 3.86 & 14.43 & 3.36 & 8.17 & 2.63 \\
\hline Maximum angle $\left({ }^{\circ}\right)$ & 9.09 & 4.39 & 8.46 & 4.59 & 2.18 & 5.22 & 8.79 & 3.86 & 8.70 & 3.63 & 1.24 & 4.09 \\
\hline Minimum angle $\left({ }^{\circ}\right)$ & -10.67 & 4.98 & -9.58 & 5.48 & -6.67 & 5.11 & -7.11 & 3.39 & -5.73 & 4.37 & -6.92 & 5.22 \\
\hline
\end{tabular}

Notes: bold and italic text denotes significant main effect for brace.

Table 2

Knee kinetics as a function of both brace and movement conditions.

\begin{tabular}{|c|c|c|c|c|c|c|c|c|c|c|c|c|}
\hline & \multicolumn{6}{|c|}{ No brace } & \multicolumn{6}{|l|}{ Brace } \\
\hline & \multicolumn{2}{|l|}{ Run } & \multicolumn{2}{|l|}{ Cut } & \multicolumn{2}{|l|}{ Jump } & \multicolumn{2}{|l|}{ Run } & \multicolumn{2}{|l|}{ Cut } & \multicolumn{2}{|l|}{ Jump } \\
\hline & Mean & SD & Mean & SD & Mean & SD & Mean & SD & Mean & SD & Mean & SD \\
\hline \multicolumn{13}{|c|}{ Sagittal plane $(-=$ flexion $/+=$ extension $)$} \\
\hline Peak moment $(\mathrm{Nm} / \mathrm{kg})$ & 2.96 & 0.68 & 3.23 & 0.66 & 2.00 & 0.56 & 2.99 & 0.78 & 3.34 & 0.71 & 1.81 & 0.48 \\
\hline \multicolumn{13}{|c|}{ Coronal plane $(+=$ adduction $/-=$ abduction $)$} \\
\hline Peak moment $(\mathrm{Nm} / \mathrm{kg})$ & -1.04 & 0.46 & -1.07 & 0.52 & 0.38 & 0.20 & -0.86 & 0.39 & -0.96 & 0.49 & 0.45 & 0.18 \\
\hline \multicolumn{13}{|c|}{ Transverse plane $(-=$ internal $/+=$ external $)$} \\
\hline Peak moment $(\mathrm{Nm} / \mathrm{kg})$ & 0.09 & 0.08 & 0.25 & 0.22 & 0.17 & 0.06 & 0.09 & 0.07 & 0.20 & 0.13 & 0.18 & 0.07 \\
\hline
\end{tabular}


thus the results may not be generalizable to a netball specific environments. Furthermore, reductions in knee range of motion may produce compensatory alterations which may place musculoskeletal structures proximal or distal to the knee joint at increased risk from injury (Santos, McIntire, Foecking, \& Liu, 2004). Nonetheless the reduction in transverse plane internal/external range of motion ties in with the subjective ratings which showed that participants found that the knee brace improved perceived stability in all movements. Selfe et al. (2011) proposed that cutaneous stimulation provided by the brace may be a factor in enhancing neuromotor control. Because knee bracing apply pressure to the supporting structures surrounding the knee Selfe et al. (2011) proposed that pressure applied specifically at the posterior of the knee may have a stimulatory influence on the hamstring and gastrocnemius muscles which contributed to increased stability and control.

A potential limitation to this work is that patellofemoral PTCF and PTS were obtained using a musculoskeletal driven model. This technique is required due to the invasive nature of obtaining direct measurements, which are not possible due to ethical constraints. Despite this, using the knee extensor mechanism as the input for the quantification of patellofemoral kinetics means that antagonist forces are unaccounted for (Sinclair \& Bottoms, 2015). This may lead to an underestimation of joint loading during the different movements (Sinclair \& Selfe, 2015). Furthermore, the current musculoskeletal model is not able to account for the compressive effects of the brace on the patella, which may limit the comparison of PTCF and PTS between conditions. Further work should focus on to improve the efficacy of musculoskeletal models of patellofemoral kinetics which may make possible further advancements in clinical biomechanics. A further possible drawback to the current work is that the midpoint between the femoral epicondyles was utilized to delineate both the distal end of the thigh segment and the proximal end of the shank. This meant that the assumption of six degrees of rotational/translational freedom was violated at the knee joint.

In conclusion, whilst previous analyses have investigated the effects of knee bracing, the current knowledge with regards to their effects in netball specific movements and participants is limited. The current investigation therefore addresses this by examining the effects of wearing a prophylactic knee brace on knee joint kinetics and kinematics during run, cut and jump movements. The current study showed firstly that knee joint kinetics were not affected by the knee brace. The findings did show however that this knee brace decreased the transverse plane internal/external rotation range of knee movement during these specific tasks and helped to increase perceived knee stability. Further study is required to determine whether reductions in transverse plane knee range of motion serve to attenuate the risk from injury in netballers.

\section{Conflict of interest}

None to declare.

\section{Ethical approval}

University of Central Lancashire, Research office - Science, Technology, Engineering, Medicine and Health Committee 278, School of Health, College of Health and Wellbeing.

\section{Uncited references}

Brouwer et al., 2007; Sinclair et al., 2014.

\section{Acknowledgements}

We would like to thank Robert Graydon for his technical assistance during data collection.

\section{References}

Brouwer, G.M., Tol, A.W., Bergink, A.P., Belo, J.N., Bernsen, R.M., Reijman, M., et al., 2007. Association between valgus and varus alignment and the development and progression of radiographic osteoarthritis of the knee. Arthritis \& Rheumatology $56,1204-1211$.

Cappozzo, A., Catani, F., Leardini, A., Benedeti, M.G., Della, C.U., 1995. Position and orientation in space of bones during movement: Anatomical frame definition and determination. Clinical Biomechanics 10, 171-178.

van Eijden, T.M., Kouwenhoven, E., Verburg, J., Weijs, W.A., 1986. A mathematical model of the patellofemoral joint. Journal of Biomechanics 19, 219-229.

Gaasbeek, R.D., Groen, B.E., Hampsink, B., Van Heerwaarden, R.J., Duysens, J., 2007. Valgus bracing in patients with medial compartment osteoarthritis of the knee: A gait analysis study of a new brace. Gait \& posture 26, 3-10.

Graydon, R., Fewtrell, D., Atkins, S., Sinclair, J., 2015. The test-retest reliability of different ankle joint center location techniques. Foot \& Ankle Online Journal $8,1-11$.

Hemmerich, A., van der Merwe, W., Batterham, M., Vaughan, C.L., 2011. Knee rotational laxity in a randomized comparison of single-versus double-bundle anterior cruciate ligament reconstruction. The American journal of sports medicine $39,48-56$.

Hetherington, S., King, S., Visentin, D., Bird, M.L., 2009. A kinematic and kinetic case study of a netball shoulder pass. International Journal of Exercise Science 2, 243-253.

Ho, K.Y., Blanchette, M.G., Powers, C.M., 2012. The influence of heel height on patellofemoral joint kinetics during walking. Gait \& Posture 36, 271-275.

Hopper, D.M., 1997. Somatotype in high performance female netball players may influence players position and the incidence of lower limb and back injuries. British Journal of Sports Medicine 31, 197-199.

Hume, P.A., Steele, J.R., 2000. A Preliminary Investigation of Injury Prevention Strategies in Netball: Are Players Heeding the Advice? Journal of Science \& Medicine in Sport 3, 406-413.

Lindenfeld, T.N., Hewett, T.E., Andriacchi, T.P., 1997. Joint loading with valgus bracing in patients with varus gonarthrosis. Clinical Orthopaedics and Related Research 344, 290-297.

McLean, S.G., Huang, X., Su, A., Van Den Bogert, A.J., 2004. Sagittal plane biomechanics cannot injure the ACL during sidestep cutting. Clinical biomechanics $19,828-838$

McManus, A., Stevenson, M.R., Finch, C.F., 2006. Incidence and risk factors for injury in non-elite netball. Journal of Science and Medicine in Sport 9, 119-124.

Neal, R.J., Sydney-Smith, M., 1992. The effects of footfall pattern and passing height on ground reaction forces in netball. Australian Journal of Science and Medicine in Sport 24, 73-78.

Pagani, C.H.F., Potthast, W., Brüggemann, G.P., 2010. The effect of valgus bracing on the knee adduction moment during gait and running in male subjects with varus alignment. Clinical Biomechanics 25, 70-76.

Paluska, S.A., McKeag, D.B., 2000. Knee braces: Current evidence and clinical recommendations for their use. American Family Physician 61, 411-418.

Powers, C.M., Lilley, J.C., Lee, T.Q., 1998. The effects of axial and multiplane loading of the extensor mechanism on the patellofemoral joint. Clinical Biomechanics $13,616-624$

Santos, M.J., McIntire, K., Foecking, J., Liu, W., 2004. The effects of ankle bracing on motion of the knee and the hip joint during trunk rotation tasks. Clinical Biomechanics 19, 964-971

Saunders, N., Otago, L., 2009. Elite netball injury Surveillance: Implications for injury prevention. Journal of Science and Medicine in Sport 12, S63.

Selfe, J., Thewlis, D., Hill, S., Whitaker, J., Sutton, C., Richards, J., 2011. A clinical study of the biomechanics of step descent using different treatment modalities for patellofemoral pain. Gait posture 34, 92-96.

Sinclair, J., 2014. Effects of barefoot and barefoot inspired footwear on knee and ankle loading during running. Clinical Biomechanics 29, 395-399.

Sinclair, J., Chockalingam, N., Naemi, R., Vincent, H., 2015. The effects of sport specific and minimalist footwear on the kinetics and kinematics of three netball specific movements. Footwear Science 7, 31-36.

Sinclair, J., Hebron, J., Taylor, P.J., 2015. The test-retest reliability of knee joint center location techniques. Journal of Applied Biomechanics 31, 117-121.

Sinclair, J., Hobbs, S.J., Protheroe, L., Edmundson, C.J., Greenhalgh, A., 2013. Determination of gait events using an externally mounted shank accelerometer. Journal of Applied Biomechanics 29, 118-122.

Sinclair, J., Selfe, J., 2015. Sex differences in knee loading in recreational runners. Journal of Biomechanics 48, 2171-2175. 
Sinclair, J., Taylor, P.J., Currigan, G., Hobbs, S.J., 2014. The test-retest reliability of three different hip joint centre location techniques. Movement \& Sport Sciences 83, 31-39.

Sinclair, J., Taylor, P.J., Hobbs, S.J., 2013. Alpha level adjustments for multiple dependent variable analyses and their applicability - A review. International Journal of Sport Science and Engineering 7, 17-20.
Warden, S.J., Hinman, R.S., Watson, M.A., Avin, K.G., Bialocerkowski, A.E., Crossley, K.M., 2008. Patellar taping and bracing for the treatment of chronic knee pain: A systematic review and meta-analysis. Arthritis Care Research 59, 73-83. 